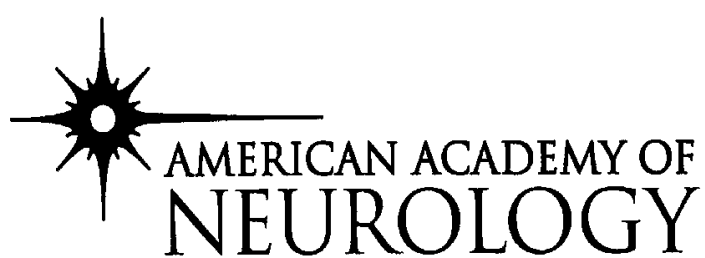

\title{
PRACTICE PARAMETER: RISK OF DRIVING AND ALZHEIMER'S DISEASE (AN EVIDENCE-BASED REVIEW)
}

\author{
Report of the Quality Standards Subcommittee of the American Academy of Neurology \\ Richard M. Dubinsky, MD; Anthony C. Stein, PhD; and Kelly Lyons, PhD
}

\begin{abstract}
Article abstract-Studies of automobile accident frequency among drivers with AD have yielded conflicting results about the risk of accidents. To develop a practice parameter regarding driving and AD the authors performed a systematic review of the literature. The authors identified well-designed, controlled studies of driving and AD using the National Library of Medicine's MEDLINE database. The authors also compared the relative rates of crashes and other performance measurements of driving ability in the populations studied. Driving was found to be mildly impaired in those drivers with probable AD at a severity of Clinical Dementia Rating (CDR) 0.5. This impairment was no greater than that tolerated in other segments of the driving population (e.g., drivers age 16 to 21 and those driving under the influence of alcohol at a blood alcohol concentration $[\mathrm{BAC}]<0.08 \%$ ). Drivers with $\mathrm{AD}$ at a severity of CDR 1 were found to pose a significant traffic safety problem both from crashes and from driving performance measurements. Key words: AD—Dementia—Driving Automobile-Practice guideline.
\end{abstract}

NEUROLOGY 2000;54:2205-2211

The Quality Standards Subcommittee (QSS) seeks to develop scientifically sound, clinically relevant practice parameters for the practice of neurology. Practice parameters are strategies for patient management that assist physicians in clinical decision making. A practice parameter is one or more specific recommendations based on analysis of evidence of a specific clinical problem. These might include diagnosis, symptoms, treatment, or procedure evaluation. This paper addresses the question: Does automobile driving by those with $\mathrm{AD}$ pose a significant traffic safety problem?

Background. A major skill needed for independence in every day adult life in North America and in many parts of the world is the ability to drive an automobile. Yet, automobile crashes are also a major cause of morbidity and mortality in most age groups. Our society has set limits on who may drive and who may not. Recently, the legislative limits have been tightened because of a lower tolerance by society for the human cost of impaired driving. As the result of concentrated effort by Mothers Against Drunk Driving (MADD) and other groups, the majority of states have reduced the limit for driving under the influence of alcohol from a blood alcohol concentration (BAC) of $0.15 \%$ to $0.08 \%$ with the remaining states at 0.1 . Similar legislative efforts to limit driving privileges have been made for patients with $\mathrm{AD}$.

Justification. This Practice Parameter has information on how safe it is for patients with AD to drive. We used an evidence-based review of the existing medical literature. The age group at highest risk for motor vehicle accidents, as defined by the frequency of accidents per million miles traveled, is 16 to 19 years. Their accident rate of 28.6 accidents per million vehicle miles traveled (MVA/MVMT) is more than seven times higher than that of 40 to 45 year-old drivers (3.7 MVA/MVMT). The accident rate increases to $15.1 \mathrm{MVA} / \mathrm{MVMT}$ for 80 to 85 year old drivers and 38.8 MVA/MVMT for drivers over age 85, while the average annual mileage driven decreases from 13,000 miles per year for drivers age 40 to 44 , to 2,615 miles for drivers 80 to $84 .^{1}$

From the Quality Standards Subcommittee of the American Academy of Neurology. Approved by the Quality Standards Subcommittee October 9, 1999. Approved by the Practice Committee October 23, 1999. Approved by the AAN Board of Directors February 26, 2000.

Received July 29, 1999. Accepted in final form April 6, 2000.

Address correspondence and reprint requests to The Quality Standards Subcommittee of the American Academy of Neurology, Wendy Edlund, 1080 Montreal Avenue, St. Paul, MN 55116

Copyright (C) 2000 by the American Academy of Neurology. 
Many individuals with early AD drive. As the dementia progresses, driving becomes impaired. Rational recommendations about driving by patients with $\mathrm{AD}$ can be made by physicians using the risk of a crash and the driving limits set by law, provided the physician understands the limits of current information. It would be inappropriate to restrict driving by one group on the basis of age or disease, while allowing another group with the same or a higher accident rate to continue to drive. On the other hand, the expected changes in driving skills with maturation (in the case of young drivers) and with degenerative decline (in drivers with AD) may influence whether restrictions are considered appropriate in different groups even if the risks in these groups are initially similar. The first is expected to improve, while the latter is expected to worsen over time.

Description of the process. We searched the National Library of Medicine's MEDLINE database from 1966 through 1998 using the terms "aged" or "Alzheimer's" and "automobile." "Dementia" was not used as a search term as it is a subheading of "aged" in the MESH listings. We did not focus solely on crash data, because automobile accidents, while causing significant morbidity and mortality, are still relatively rare events even in impaired populations. The evidence was stratified by quality and divided into Class I, II, and III (appendix 1).

Articles published before 1966 and articles not found on MEDLINE were identified by reviewing the references in each of the studies found through the MEDLINE search using the criteria listed above. Articles were excluded if they were only reviews, editorials, or opinions.

From the articles identified using the search criteria listed above, we extracted the following data: cohort size, characteristics of study subjects, selection method of study subjects and controls, blinding, dementia severity measurement, and driving (crash or accident) assessment. To compare studies using different indices of dementia severity, we used the conversion table proposed by Reisberg, et al. to convert to the Clinical Dementia Rating (CDR) scale (table) ${ }^{2,3}$ A CDR of 0.5 is roughly equivalent to a Mini-Mental State Examination (MMSE) ${ }^{4}$ score of 25 , while a CDR stage 1 is roughly equivalent to a MMSE of less than 25 but greater than $19 .^{2}$ The use of CDR stage was chosen over the MMSE because it is a functional assessment. The MMSE was developed as a screening tool for dementia and it does not take into account a functional assessment of the subject.

We also used each study's results to calculate measures that allowed us to compare the studies. We specifically looked for the number of crashes reported and the miles driven. The calculated measurements included the relative rates of crashes, or of impaired drivers, with $95 \% \mathrm{CI}$. These values were calculated using $2 \times 2$ tables of each study's measurement. Calculations for relative rate and Cl were based upon the table:

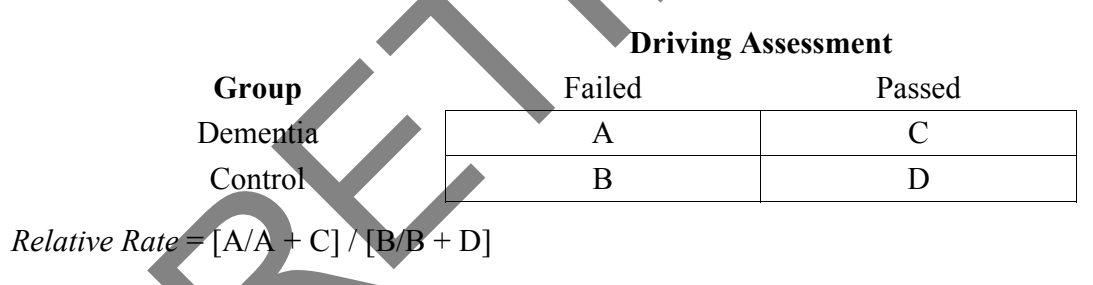

Scientific reports. We identified 218 studies in our original search; 21 additional articles were added from review of references in the selected articles and two articles were included that were published after the original MEDLINE search. Fourteen articles met the criteria for Class I, II, or III evidence, in that they provided data relevant to the issue at hand. The 14 articles were divided into the following groups: crash statistics, evaluation of driving performance, and analysis of driving task components.

Crash statistic studies in drivers with AD. In 1963, Waller reported the results of a review of driving records of all drivers in California requiring a medical review. In his 1967 follow-up study, Waller reported the results of a survey mailed to residents of a retirement community (Class IIb). ${ }^{5}$ Ten percent of the residents were randomly selected for the mailing. The return rate was $53.7 \%$. Eighty-two subjects classified as "senile" were compared to 83 cognitively normal older individuals. He did not publish the definition of the "senile group." The accident rate per million vehicle miles traveled is the standard used to measure accidents as reflected by driving exposure. Accident rates without data on exposure do not allow accurate comparison of groups of drivers. Driving exposure data were collected in Waller's study, unlike most of the studies that were reviewed. The "senile" group reported 19.3 MVA/MVMT while the cognitively intact healthy elder group had $12.1 \mathrm{MVA} / \mathrm{MVMT}$ (relative rate $=1.56 ; 95 \% \mathrm{CI}$ could not be calculated from the information in the article). This rate is high demonstrating an increase in the true accident rate of "senile" drivers when compared to cognitively intact elder drivers.

In a 1988 questionnaire study administered to 30 patients with probable $\mathrm{AD}$ and to their spouses/caregivers and to a community-based control group. ${ }^{6}$ (Class IIb), crashes were recorded over the time course from the onset of dementia (average 5.5 years). The mean duration of dementia was 4.0 years $( \pm 1.8)$ at the time of the first crash. The 
average MMSE score was 19.9 ( \pm 6.3$)$ corresponding to a CDR of $1.0(\mathrm{RR}=7 ; 95 \%$ CI: 5.26 to 35.2). The eight-fold increase in the crash rate for the group with Alzheimer's implies a greater risk of crashes compared to other drivers.

In 1988, a 20-item screening questionnaire was administered to the caregivers of 72 consecutive patients referred to a dementia clinic. ${ }^{7}$ The subjects had either AD (National Institute of Neurological and Communicative Disorders and Stroke-Alzheimer's Disease and Related Disorders Association [NINCDS-ADRDA] criteria, 53\%), multi-infarct dementia (8\%), a combination of AD and multi-infarct dementia (4\%), other causes of dementia (9\%), or dementia of unknown etiology (26\%). A control group was not used. Driving exposure was not determined (Class $\mathrm{IIb}$ ). Thirty per cent of their subjects were involved in motor vehicle accidents after the onset of dementia (average duration of $3.4 \pm 2.4$ years). An additional $11 \%$ were thought by their caregivers to have caused an accident. This study also demonstrates the risk of accidents and dangerous driving behavior by those with AD that still drive.

In 1991 a structured interview was used to assess driving behavior and crashes in 522 consecutive referrals to a dementia $\operatorname{clinic}^{8}$ (Class IIb). A control group was not included nor was there information on driving exposure that would allow comparison to published crash rates in elderly controls. They reported that $21(22.6 \%)$ of the 93 subjects who were still driving at the time of the interview, had had a single or multiple car motor vehicle accident in the six months before the interview. Again, driving appears to be hazardous in this group.

Table Clinical Dementia Rating

\begin{tabular}{|c|c|c|c|c|}
\hline \multirow[b]{2}{*}{ Categories } & \multicolumn{4}{|c|}{ Impairment } \\
\hline & 0 & 0.5 & 1 & 2 \\
\hline $\begin{array}{l}\text { Memory (major } \\
\text { category) }\end{array}$ & $\begin{array}{l}\text { No memory loss or slight } \\
\text { inconsistent } \\
\text { forgetfulness }\end{array}$ & $\begin{array}{l}\text { Consistent slight } \\
\text { forgetfulness, partial } \\
\text { recollection of events, } \\
\text { "benign" forgetfulness }\end{array}$ & $\begin{array}{l}\text { Moderate memory loss; } \\
\text { more marked for recent } \\
\text { events; defect interferes } \\
\text { with everyday activities }\end{array}$ & $\begin{array}{l}\text { Severe memory loss; only } \\
\text { highly learned material } \\
\text { retained; new material } \\
\text { rapidly lost }\end{array}$ \\
\hline \multicolumn{5}{|l|}{ Secondary categories: } \\
\hline Orientation & Fully oriented & $\begin{array}{l}\text { Fully oriente } \\
\text { slight diffi } \\
\text { time relati }\end{array}$ & $\begin{array}{l}\text { oderate difficulty with } \\
\text { time relationships; }\end{array}$ & $\begin{array}{l}\text { Severe difficulty with time } \\
\text { relationships; usually } \\
\text { disoriented to time, often } \\
\text { to place }\end{array}$ \\
\hline $\begin{array}{l}\text { Judgment and } \\
\text { problem solving }\end{array}$ & $\begin{array}{l}\text { Solves everyday problems } \\
\text { and handles business } \\
\text { and financial affairs, } \\
\text { well; judgment good in } \\
\text { relation to past } \\
\text { performance }\end{array}$ & он & $\begin{array}{l}\text { Moderate difficulties in } \\
\text { handling problems, } \\
\text { similarities, and } \\
\text { differences; social } \\
\text { judgment usually } \\
\text { maintained }\end{array}$ & $\begin{array}{l}\text { Severely impaired in } \\
\text { handling problems, } \\
\text { similarities, and } \\
\text { differences; social } \\
\text { judgment usually } \\
\text { impaired }\end{array}$ \\
\hline Community affairs & $\begin{array}{l}\text { Independent function } \\
\text { usual level in job, } \\
\text { shopping, and volt } \\
\text { and social groups }\end{array}$ & $\begin{array}{l}\text { impairment in these } \\
\text { vities }\end{array}$ & $\begin{array}{l}\text { Unable to function } \\
\text { independently at these } \\
\text { activities although may } \\
\text { still be engaged in some; } \\
\text { appears normal to casual } \\
\text { inspection }\end{array}$ & $\begin{array}{l}\text { No pretense of independent } \\
\text { function outside home. } \\
\text { Appears well enough to } \\
\text { be taken to function } \\
\text { outside a family home }\end{array}$ \\
\hline Home and hobbies & $\begin{array}{l}\text { Life at home, hobbies, and } \\
\text { intellectual interests are } \\
\text { well maintained }\end{array}$ & $\begin{array}{l}\text { Life at home, hobbies, and } \\
\text { intellectual interests } \\
\text { slightly impaired }\end{array}$ & $\begin{array}{l}\text { Mild but definite } \\
\text { impairment if function at } \\
\text { home, more difficult } \\
\text { chores abandoned, more } \\
\text { complicated hobbies and } \\
\text { interests abandoned }\end{array}$ & $\begin{array}{l}\text { Only simple chores } \\
\text { preserved; very } \\
\text { restricted interests, } \\
\text { poorly maintained }\end{array}$ \\
\hline Personal care & Fully capable of self-care & Fully capable of self-care & Needs prompting & $\begin{array}{l}\text { Requires assistance in } \\
\text { dressing, hygiene, } \\
\text { keeping of personal } \\
\text { effects }\end{array}$ \\
\hline
\end{tabular}

Impairment is the decline from the subject's usual level of functioning. CDR $=$ Memory score unless three or more of the secondary categories score above or below the Memory score, in which case the CDR = the majority of the secondary categories. For complete instructions please see Morris. ${ }^{3}$

In a 1992 study, a questionnaire was administered to 67 drivers with AD and to their caregivers, and compared to the results with 100 elderly controls recruited from the community ${ }^{9,10}$ (Class IIa). An accident rate was calculated based upon exposure. Nineteen drivers with AD (CDR 0.5) were still driving at the time of the study. Their accident rate was 26.6 MVA/MVMT (95\% CI: 0.6 to 69.9) compared to 8.5 MVA/MVMT (95\% CI: 5.3 to 13.8) for the 98 controls who were still driving at the time of the study $(\mathrm{RR}=3.13)$. The results of this age-matched cohort survey are consistent with the studies reviewed above.

Drachman et al. surveyed the driving habits of patients who met the NINCDS-ADRDA criteria of possible or probable $\mathrm{AD}^{11}$ (Class IIa). Patients with $\mathrm{AD}$ and their caregivers were interviewed in seven $\mathrm{AD}$ research centers. 
Their responses were compared to those of normal elders recruited by the same centers. Subjects with dementia were matched by gender and age, oldest to oldest, next oldest to next oldest, etc. at each site. There was a linear increase in the rate of crashes among drivers with AD over the 6-year period studied. CDR staging was not used, but given the short time that AD was reported in these patients, most of their subjects would be expected to be CDR 0.5 to CDR 1.0. There was a 2.3 fold difference (95\% CI: 1.11 to 10.2$)$ in the relative risk of crashes between the two groups. The authors acknowledged that although the number of crashes per year was greater in the drivers with $\mathrm{AD}$ when compared to the controls, the crash rate per year was still less than that reported for 16 to 24 -year-old drivers. This study has two major methodological shortcomings: inadequate matching of subjects and controls and lack of a measurement of driving exposure. While similar percentages of each group were reported for the ranges of $<5,000$ miles, between 5,000 and 10,000 miles, and >10,000 miles of driving per year, the accident rate per million vehicle miles of travel can not be calculated without a comparison of driving exposure between the groups. The results of this study are similar to those of the other studies.

A 1995 review of driving records was performed of patients referred to a dementia clinic, compared with the records to controls, matched for gender, age, and place of residence (Class IIa). ${ }^{12}$ Because there was a single insurer for the Province of British Columbia, all records for insured drivers could be reviewed. Of 165 patients (86 with probable and 68 with possible AD by NINCDS-ADRDA criteria; 11 with dementia but unlikely to have AD) 61 $(37.0 \%)$ had crashes compared to $25(15.1 \%)$ controls. The control group was matched to the subjects by age, gender, and location of residence in the province. Estimates of miles driven by each group were not obtained. They calculated a crash rate based on the number of months of driving after the diagnosis was made. The subjects with $\mathrm{AD}$ had 0.15 crashes per year compared to 0.06 crashes per year for the matched controls $(\mathrm{RR}=2.26 ; 95 \% \mathrm{CI}$ : 0.88 to 5.97). Though this study is limited by the comparison of crashes per year instead of the standard of accidents per miles driven, the results agree with other studies of accident rates.

A 1996 review compared the driving records in police files of 143 licensed drivers with AD who were either currently driving or had driven within five years of an evaluation at the Alzheimer's clinic at the University of Michigan $^{13}$ to five records matched by the Michigan Office of the Secretary of State by gender, age ( \pm 6 years) and county of residence (Class IIa). The average MMSE of the subjects with AD who were still driving, and those who had stopped driving, would place them in CDR stage 0.5 . The reported accident and traffic violation rates were similar for the two groups. However, driving exposure was not used to calculate the accident rate, even though the authors had collected information on the amount of recent travel (kilometers per week) of those who were still driving. They hypothesized that if exposure were taken into account, there would have been an increase in the crash rate for the drivers with $\mathrm{AD}$ drivers, but the measured $\mathrm{RR}=1.0$ (95\% CI: 0.986 to 1.015) suggested no significant difference. Thus this is the only study cited so far that did not show more crashes for the drivers with dementia than for the normal population in the study.

Almost all of these studies demonstrate an increased crash rate for drivers with AD.

Driving performance studies in drivers with $A D$. The first performance test of driving in a group of drivers with mild dementia (presumably most hadearly AD, CDR 0.5) compared to drivers with diabetic retinopathy, multiinfarct dementia and normal elders was reported in $1995^{14}$ (Class IIb). The authors used an on-the-road, $2.7 \mathrm{mile}$ fixed course test on the grounds of a Veteran's Administration Medical Center. Investigators experienced in assessing driving rated the driver's performance. They were blinded to the clinical status of the drivers. The drivers with mild dementia performed at a significantly lower level than the control group and the diabetic retinopathy group. Unfortunately, pass/fail criteria for the on-the-road test were not included in the article. Without pass/fail criteria, the relative rate and confidence interval could not be calculated, despite the significantly lower level of driving performance for the drivers with dementia.

In a 1997 study the driving evaluation of 19 drivers with mild dementia was reported (Class III). ${ }^{15}$ The drivers underwent extensive testing that included an on-the-road driving assessment. Only seven of the subjects passed. The passing rate of safe drivers was not given. This study also suggests substandard driving performance by drivers with AD.

In 1996 Rizzo et al. used a high fidelity driving simulator, with six degrees of freedom, to assess the driving ability of 21 drivers with AD in comparison to 18 elderly controls without dementia (Class IIa). ${ }^{16}$ The drivers with dementia (CDR 0.5 and 1.0) had twice as many "close calls" as the normal drivers. Six of the drivers with dementia were involved in crashes on the simulator, but none of the controls were. The drivers with dementia also had significantly more lane boundary violations (going over the yellow or white lines), but specific data were not given. This is unfortunate in that lane boundary violations are a categorical measurement of the standard deviation of lane position, a continuous measurement of tracking error when a driver is attempting to stay in their lane. Driving under the influence of alcohol at a BAC of $0.08 \%$ is associated with a standard deviation of lane position of 1.04 feet, while driving with a BAC of $0.1 \%$ is associated with a standard deviation of lane position of 2.0 feet. ${ }^{17,18}$ If the data 
on lane boundary violations were included in the article, a direct comparison to the equivalent impairment associated with driving under the influence of alcohol could have been made. This observational cohort study reported significant errors by drivers with $\mathrm{AD}$ on relatively simple components of the driving task that either caused crashes or near misses.

Hunt et al. performed an on-the road-test of driving ability of drivers with AD, CDR stage $0.5(\mathrm{n}=36)$ and 1.0 $(n=29)$, compared with that of normal elders $(n=58)$ (Class I). ${ }^{19}$ They used a preliminary closed course to familiarize the subjects with the controls and handling of the test vehicle. The subjects then drove a fixed course on the open road. Driving ability was judged by driving instructors and a physical therapist with experience in the evaluation of handicapped drivers. Both were blinded to the cognitive abilities of the test subjects. Two of the controls failed the open road test compared with seven $(19 \%, \mathrm{RR}=5.64 ; 95 \% \mathrm{CI}=4.4$ to 31.3$)$ with very mild dementia (CDR 0.5), and 12 with moderate dementia (CDR 1.0) $(41 \%, \mathrm{RR}=12 ; 95 \% \mathrm{CI}=9.1$ to 62.1$)$.

These four studies demonstrate significant impairment in the driving ability of drivers with AD.

Driving task testing in drivers with $A D$. The flaws noted in the above studies, combined with the relatively minor motoric problems in mild to moderate $\mathrm{AD}$, have led some investigators to concentrate on visual perception of drivers with $\mathrm{AD}$. This is based upon the attentional model of driving performance proposed by Parasuraman and Nester. ${ }^{20-22}$

Ball et al. investigated visual processing in a group of 302 drivers in Alabama who were stratified based on the number of recent crashes (Class IIa). ${ }^{23}$ The main visual assessment was the Useful Field of View test (UFOV). This test measures the speed and accuracy of detecting visual stimuli within and adjacent to central vision. A decrease in the UFOV by $40 \%$ or more and impaired mental status (defined as a score $>9$ on the Mattis Organic Mental Status Syndrome Evaluation) together accounted for $28 \%$ of the variance in the number of crashes in their study population. However, in their follow-up study, mental status at the time of the initial study was not predictive of crashes during the 3 years of follow-up (Class I). ${ }^{24}$ Thus, although visual processing combined with impaired mental status can account for a substantial amount of the variance in crash rates in an elderly population, the combination did not predict future crashes.

In a 1998 study the ability to recognize traffic signs by drivers with early AD was compared to normal aged controls (Class IIb) ${ }^{25}$ The test used was the standard 10 traffic sign test administered by the Indiana Bureau of Motor Vehicles as part of the drivers license renewal test. Twenty-one of 37 subjects with AD failed the test $(\leq 6$ correct answers) versus 5 of 47 control subjects. $(R R=5.5$; $95 \%$ CI: 3.1 to 18.1 ) These drivers would have had their license revoked as a result of their failure. Thus, we can use this study as an application of a governmental pass/fail test on a selected population. The mean MMSE scores of the subjects with AD were 20.2 for those who failed the test and 25.1 for those who passed, placing the groups in CDR stage 1 or 0.5 respectively. The high rate of errors on a simple traffic sign recognition test agrees with the driving errors reported in the performance studies and in the tendency for drivers with dementia to become lost as cited in the articles above.

These three studies demonstrate significant problems with visual processing in drivers with AD.

Statement of the evidence. In patients with AD who continue to drive, there is clear evidence based on one Class I (Hunt et al.) and several Class II studies that there is an increased risk of crashes compared to age-matched controls. The relative risk of crashes for drivers with $\mathrm{AD}$ of CDR stage 1.0 is greater than our society tolerates for any group of drivers. Drivers with early AD, at CDR stage 0.5 , have an increased risk of accidents similar to that society accepts for 16 to 19 year old drivers and for those drivers intoxicated with alcohol at a $\mathrm{BAC}<0.08 \% .{ }^{18}$ This increased risk is based upon crash statistics, performance studies of drivers with $\mathrm{AD}$, and testing of components of the driving task.

Almost all of the reports that met the inclusion or exclusion criteria of our analysis found that cognitively impaired drivers fared worse than controls. However, most of the accident statistics research on drivers with AD have not taken driving exposure into account, have not relied on blinded evaluators, and have not included an adequate sample size. It is also difficult to compare the severity of dementia across studies. Therefore, whether the drivers with $\mathrm{AD}$ in most of the studies we reviewed really had an accident rate greater than society tolerates in younger drivers (age 16 to 19 years) is moot, but there is no doubt that the accident rate in the group with dementia is high. As to the relationship of degree of dementia to the accident rate, the CDR stages are based upon many levels of functioning of a patient with AD. Unfortunately, conversion of other scales to an equivalent of CDR stage 0.5 requires the combining of several dissimilar groups: mild cognitive impairment, questionable $\mathrm{AD}$, and mild $\mathrm{AD}$. Difficulties were also encountered converting the dissimilar scales used in these studies to an equivalent CDR. Given these difficulties, recommendations are made using the criteria for strength of evidence (appendix 2). 
The published evidence on driving performance in those with $\mathrm{AD}$ supports the following recommendations. Decisions regarding license restrictions for drivers with $\mathrm{AD}$ must always be made in compliance with appropriate state laws and in consultation with the individual patient.

1) Patients and their families should be told that patients with $A D$ with a severity of CDR 1 or greater have a substantially increased accident rate and driving performance errors, and therefore, discontinuation of driving should be strongly considered (Standard).

2) Patients and their families should be told that patients with possible AD with a severity of CDR 0.5 pose a significant traffic safety problem when compared to other elder drivers. Referral of the patient for a driving performance evaluation by a qualified examiner should be considered (Guideline). Because of the high likelihood of progression to a severity of CDR 1 within a few years, clinicians should reassess dementia severity and appropriateness of continued driving every 6 months (Standard).

Future research. Further research is needed to determine if there are subsets of patients with AD with a severity of CDR 1 who can drive safely, or who can drive safely with enforceable restrictions (e.g., nonhighway driving or driving within a limited geographic area). Analysis by gender would be of interest, as gender is a factor in severity of dementia when age is controlled. Crash type and severity is another area of needed research. It may be possible that if there are typical accidents due to dementia, that driving limitation or technologic solutions could allow drivers to decrease their crash risk. Research is also needed for subjects with vascular dementia, fronto-temporal dementia, Lewy body dementia, and the subcortical dementia in PD. Other related questions that need to be addressed include: reliable predictors of future unsafe driving, the efficacy of frequent driving performance assessment in demented drivers, and the effects of driver retraining programs. This research can be accomplished using both on the road and driving simulator performance measurements. Additional research is needed to determine crash rates taking into account driving exposure. All of these studies should be prospective, use appropriate control groups, and have adequate sample size. The rater(s) must be blinded to the clinical status of the subject, and the CDR staging should be used to allow for comparison with other studies. Studies designed to look primarily at frequency of crashes should use a combination of self-reporting (patient and earegiver) and accidents reported to the Department of Motor Vehicles.

The cost to society of driving by individuals with mild dementia needs to be determined. Whether periodic testing of cognitive decline in older individuals can reduce such costs is another question for future research.

Disclaimer. This statement is provided as an educational service of the American Academy of Neurology. It is based on an assessment of current scientific and clinical information. It is not intended to include all possible proper methods of care for choosing a specific procedure. Neither is it intended to exclude any reasonable alternative methodologies. The American Academy of Neurology recognizes that specific patient care decisions are the prerogative of the patient and the physician caring for the patient, based upon all of the circumstances involved.

\section{Acknowledgment}

The authors thank the members of the American Academy of Neurology Quality Standards Subcommittee and the many individual members of the American Academy of Neurology who provided review and comment on the manuscript. Quality Standards Subcommittee: Catherine Zahn, MD (Co-Chair); Gary Franklin, MD, MPH (Co-Chair); Milton Alter, MD, PhD; Stephen Ashwal, MD; John Calverly, MD; Jacqueline French, MD; Michael Greenberg, MD; Gary Gronseth, MD; Debbie Hirtz, MD; Robert C. Miller, MD; Jay Rosenberg, MD; James Stevens, MD; William Weiner, MD.

\section{Appendix 1: classes of evidence}

Class I: Must have all of a to d: a) a prospective study of well-defined cohorts that includes a description of the nature of the population, the inclusion or exclusion criteria, demographic characteristics such as age, sex, and commonly used staging of dementia severity; b) the sample size must be adequate with enough statistical power to justify the conclusions or for identification of subgroups for whom testing does or does not yield significant information; c) the interpretation of evaluations performed must be done blinded to subject status; d) the methodology used for evaluations must be adequate.

Class II: a) a retrospective study of a well-defined cohort which otherwise meets criteria for class $1 \mathrm{a}, 1 \mathrm{~b}$, and 1d; b) a prospective or retrospective study which lacks any of the following: adequate sample size, a well defined control group, adequate methodology, blinding of evaluators, a description of the inclusion or exclusion criteria, and information such as age, sex, and commonly used staging of dementia severity.

Class III: May have either a, b, or c: a) criteria of a class II article published in a nonpeer reviewed format; b) a small cohort or case report; c) evidence from expert opinion or consensus.

Appendix 2: levels of recommendations Recommendation (level of evidence) 
Standard: A principle for patient management that reflects a high degree of clinical certainty (usually this requires class I evidence that directly addresses the clinical questions, or overwhelming class II evidence when circumstance preclude randomized clinical trials.

Guideline: A recommendation for patient management that reflects moderate clinical certainty (usually this requires class II evidence or a strong consensus of class III evidence).

Practice option: A strategy for patient management for which the clinical utility is uncertain (inconclusive or conflicting evidence or opinion).

Practice advisory: A practice recommendation for emerging or newly approved therapies or technologies based on evidence from at least one class I study. The evidence may demonstrate only a modest statistical effect or limited (partial) clinical response, or significant cost-benefit questions may exist. Substantial (or potential) disagreement among practitioners or between payers and practitioners may exist.

\section{References}

1. Cerrelli E. Older drivers, the age factor in traffic safety. Springfield, Virginia: National Highway Traffic Safety Administration, National Technical Information Service, 1989.

2. Reisberg B, Sclan SG, Franssen E, Kluger A, Ferris S. Dementia staging in chronic care populations. Alzheimer Dis Assoc Disord 1994;8(suppl 1):S188-205.

3. Morris JC. The Clinical Dementia Rating (CDR): current version and scoring rules. Neurology 1993;43:2412-2414.

4. Folstein JF, Folstein SE, McHugh PR. "Mini-mental state" - a practical method for grading cognitive state of patients for the clinician. J Psychiatr Res 1975;43:882-885.

5. Waller JA. Cardiovascular disease, aging, and traffic accidents. J Chron Dis 1967;20:615-620.

6. Friedland RP, Koss E, Kumar A, et al. Motor vehicle crashes in dementia of the Alzheimer type. Ann Neurol 1988;24:782786.

7. Lucas-Blaustein MJ, Filipp L, Dungan C, Tune L. Driving in patients with dementia. J Am Geriatr Soc 1988;36:1087-1091.

8. Gilley DW, Wilson RS, Bennett DA, et al. Cessation of driving and unsafe motor vehicle operation by dementia patients. Arch Intern Med 1991;151:941-946.

9. Dubinsky RM, Williamson A, Gray CS, Glatt SL. Driving in Alzheimer's disease. J Am Geriatr Soc 1992;40:1112-1116.

10. Dubinsky RM, Williamson A, Gray C, Glatt S. Driving with cognitive impairment-reply. J Am Geriatrics Soc 1993;41:890891.

11. Drachman DA, Swearer JM. Driving and Alzheimer's disease: the risk of crashes. Neurology 1993;43:2448-2456.

12. Tuokko H, Tallman K, Beattie BL, Cooper P, Weir J. An examination of driving records in a dementia clinic. J Gerontol B Psychol Sci Soc Sci 1995;50:S173-181.

13. Trobe JD, Waller PF, Cook-Flannagan CA, Teshima SM, Bieliauskas LA. Crashes and violations among drivers with Alzheimer disease. Arch Neurol 1996;53:411-416.

14. Fitten LJ, Perryman KM, Wilkinson CJ, et a1 Alzheimer and vascular dementias and driving. A prospective road and laboratory study. JAMA 1995;273:1360-1365.

15. Fox GK, Bowden SC, Bashford GM, Smith DS. Alzheimer's disease and driving: prediction and assessment of driving performance. J Am Geriatr Soc 1997;45:949-953.

16. Rizzo M, Reinach S, McGehee D, Dawson J. Simulated car crashes and crash predictors on drivers with Alzheimer disease. Arch Neurol 1997;54:545-551

17. Stein AC, Allen RW. The effects of alcohol on driver decision making and risk taking. In: Noordzij PC, Roszbach R, eds. Alcohol, Drugs and Traffic Safety T86. New York: Excerpta Medica, 1987;171-181.

18. Allen RW, Parseghian Z, Stein AC, Rosenthal TJ. Driving simulator study of the performance effects of low blood alcohol concentration. In: HFES, ed. Proceedings of the 40th Annual Meeting of the Human Factors and Ergonomics Society. Santa Monica: HFES, September 28-October 3, 1996.

19. Hunt LA, Murphy CF, Carr D, Duchek JM, Buckles V, Morris JC. Reliability of the Washington University Road Test. A performance-based assessment for drivers with dementia of the Alzheimer type. Arch Neurol 1997;54:707-712.

20. Parasuraman R, Nestor PG. Attention and driving skills in aging and Alzheimer's disease. Hum Factors 1991;33:539-557.

21. Parasuraman R, Greenwood P, Haxby JV. Visuospatial attention in dementia of the Alzheimer's type. Brain 1992;115:711733.

22. Parasuraman R, Nestor P. Attention and driving. Assessment in elderly individuals with dementia. Clin Geriatr Med 1993;9:377-387.

23. Ball K, Owsley C, Sloane ME, Roenker DL, Bruni JR. Visual attention problems as a predictor of vehicle crashes in older drivers. Invest Ophthalmol Vis Sci 1993;34:3110-3123.

24. Owsley C, Ball K, McGwin G Jr, et al. Visual processing impairment and risk of motor vehicle crash among older adults. JAMA 1998;279:1083-1088.

25. Brashear A, Unverzagt FW, Kuhn ER, et al. Impaired traffic sign recognition in drivers with dementia. Am J Alzheimer Dis 1998;13:131-137. 


\section{Neurology}

Practice parameter: Risk of driving and Alzheimer's disease (an evidence-based review) [RETIRED]: Report of the Quality Standards Subcommittee of the American Academy of Neurology

Richard M. Dubinsky, Anthony C. Stein and Kelly Lyons

Neurology 2000;54;2205-2211

DOI 10.1212/WNL.54.12.2205

This information is current as of June 27, 2000

\section{Updated Information \&} Services

Citations

Permissions \& Licensing

Reprints including high resolution figures, can be found at: http://n.neurology.org/content/54/12/2205.full

This article has been cited by 16 HighWire-hosted articles: http://n.neurology.org/content/54/12/2205.full\#\#otherarticles

Information about reproducing this articlein parts (figures,tables) or in its entirety can be found online at:

http://www.neurology.org/about/about_the_journal\#permissions

Information about ordering reprints can be found online:

http://n.neurology.org/subscribers/advertise

Neurology ${ }^{\circledR}$ is the official journal of the American Academy of Neurology. Published continuously since 1951, it is now a weekly with 48 issues per year. Copyright. All rights reserved. Print ISSN: 0028-3878. Online ISSN: $1526-632 X$.

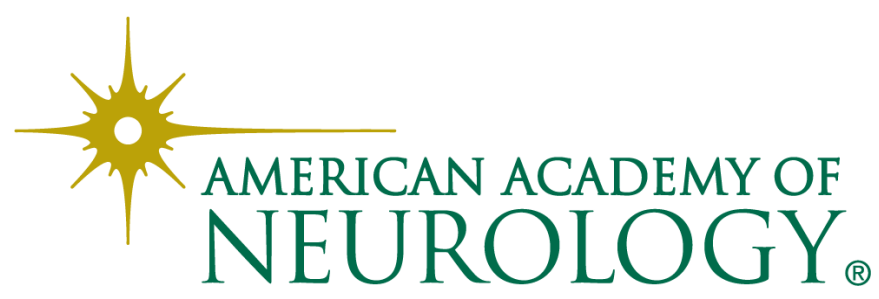




\section{Neurology}

Practice parameter: Risk of driving and Alzheimer's disease (an evidence-based review) [RETIRED]: Report of the Quality Standards Subcommittee of the American Academy of Neurology

Richard M. Dubinsky, Anthony C. Stein and Kelly Lyons

Neurology 2000;54;2205-2211

DOI 10.1212/WNL.54.12.2205

This information is current as of June 27, 2000

Updated Information \&

Services

Citations

Permissions \& Licensing

Reprints including high resolution figures, can be found at:

http://n.neurology.org/content/54/12/2205.full

This article has been cited by 16 HighWire-hosted articles:

http://n.neurology.org/content/54/12/2205.full\#\#otherarticles

Information about reproducing this article in parts (figures, tables) or in its entirety can be found online at:

http://www.neurology.org/about/about_the_journal\#permissions

Information about ordering reprints can be found online:

http://n.neurology.org/subscribers/advertise

Neurology ${ }^{\circledR}$ is the official journal of the American Academy of Neurology. Published continuously since 1951, it is now a weekly with 48 issues per year. Copyright . All rights reserved. Print ISSN: 0028-3878. Online ISSN: $1526-632 \mathrm{X}$.

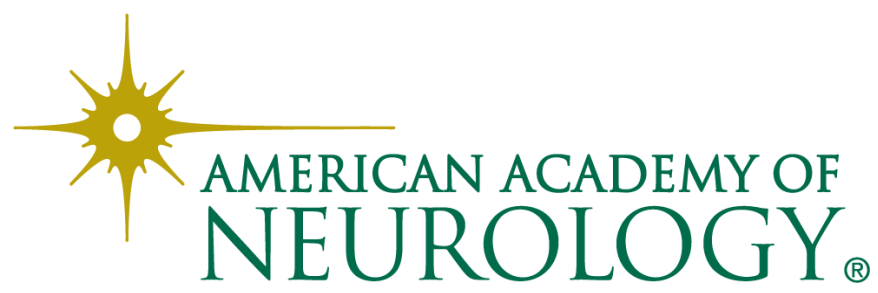

